\title{
Synergistic effect of adsorption and photocatalysis for the degradation of toluene by TiO2 loaded on ACF modified by $\mathrm{Zn}(\mathrm{CH} 3 \mathrm{COO}) 2$
}

\section{Yuxi Bi ( $D$ 15211476662@163.com )}

China University of Petroleum Huadong - Qingdao Campus https://orcid.org/0000-0003-1800-9153

\section{Encheng Sun}

China University of Petroleum Huadong - Qingdao Campus

\section{Shuai Zhang}

China University of Petroleum Huadong - Qingdao Campus

Feiran Du

China University of Petroleum Huadong - Qingdao Campus

\section{Haidi Wei}

China University of Petroleum Huadong - Qingdao Campus

\section{Fang Liu}

China University of Petroleum Huadong - Qingdao Campus

Chaocheng Zhao

China University of Petroleum Huadong - Qingdao Campus

\section{Research Article}

Keywords: Modified ACF, TiO2, Photocatalysis, Adsorption, Toluene, Mechanism

Posted Date: April 26th, 2021

DOI: https://doi.org/10.21203/rs.3.rs-361242/v1

License: (a) This work is licensed under a Creative Commons Attribution 4.0 International License.

Read Full License 


\section{Abstract}

Activated carbon fiber (ACF) was modified by $\mathrm{Zn}\left(\mathrm{NO}_{3}\right)_{2}, \mathrm{ZnCl} 2$ and $\left.\mathrm{Zn}\left(\mathrm{CH}_{3} \mathrm{COO}\right)_{2}\right)$, respectively, and then $\mathrm{TiO}_{2}$ was loaded on the modified ACFs. The adsorption and photocatalysis performance were explored through the removal of toluene, and $\mathrm{TiO}_{2} / \mathrm{ACF}_{-}{ }_{\mathrm{Ac}}$ modified by $\left.\mathrm{Zn}\left(\mathrm{CH}_{3} \mathrm{COO}\right)_{2}\right)$ with the best toluene performance was selected. The characterization results indicated that $\mathrm{TiO}_{2}$ was mainly loaded on the surface with large amount of oxygen-containing functional groups in anatase phase. The photoelectric chemical experiment results demonstrated that the modified ACFs remarkably improved the charge transmission and the separation efficiency of electrons and holes, and enhanced the utilization rate of sunlight. The adsorption saturation time reached 40 hours and photodegradation rate was $70 \%$. The direct desorption of generated small molecule substances such as $\mathrm{H}_{2} \mathrm{O}$ and $\mathrm{CO}_{2}$ from the surface of the composites can achieve the in-situ regeneration of the adsorbent. Overall, the bifunctional catalysts provide a prospective way for the treatment of VOCs.

\section{Introduction}

Volatile organic compounds (VOCs) can be divided into alkanes, aromatics, olefins, esters, etc, mainly from petrochemical industry, automobile exhaust, coating manufacturing and so on. Most VOCs are toxic and carcinogenic, and some VOCs are also inflammable and explosive(Liu et al. 2019, Tong et al. 2019). When the concentration of VOCs in the environment reaches a certain level, it will cause serious damage to human liver, kidney, brain and nervous system. VOCs are important precursor to form ozone $\left(\mathrm{O}_{3}\right)$ and fine particles, and may also cause environmental pollution problems, such as haze and photochemical smog(Fan et al. 2020, Qun et al. 2019). Therefore, an effective VOCs treatment method is urgently needed for human health and ecological environment safety.

At present, the treatment technologies of VOCs mainly include adsorption, low temperature condensation, membrane separation, catalytic oxidation and others(Hendry et al. 2019, Lelicińska-Serafin et al. 2019, Mok et al. 2020). Compared with other methods, photocatalysis oxidation technology has a great deal of merits, for instance simple operation, high efficiency, energy saving, safety, low cost and mild reaction conditions(Weon et al. 2017). The conventional catalysts for VOCs treatment mainly include $\mathrm{TiO}_{2}, \mathrm{~g}-\mathrm{C}_{3} \mathrm{~N}_{4}$, bismuth-based materials, graphene and its composite materials. $\mathrm{TiO}_{2}$ has become an ideal photocatalyst owing to its high photocatalytic activity, stable chemical properties, strong corrosion resistance, low cost and no secondary pollution, so it has been extensively used in effluent disposal, air purge and antibacterial fields(Behnam et al. 2018, Li et al. 2020a, Wu et al. 2018). However, the defects of $\mathrm{TiO}_{2}$, such as wide band gap, low utilization rate of sunlight, aggregation and photogenerated electron $\left(\mathrm{e}^{-}\right)$and hole $\left(\mathrm{h}^{+}\right)$recombination, seriously restrict its practical application(Feizpour et al. 2019).

In addition, adsorption method is an important way for the purification of VOCs owing to its mature process, low cost, high removal rate and so on(Cheng et al. 2020). Activated carbon fiber (ACF) is an advanced type of porous fibrous material with many advantages, such as high-efficiency adsorption, 
large surface area, excellent adsorption properties, standout porous structure and bountiful surface functional groups. It is an environment-friendly adsorption, photocatalytic and carrier material, and can be used for heavy metal wastewater, organic pollutants and waste gas treatment(Liu et al. 2018, Miranda Zoppas et al. 2020). In order to improve the adsorption effect and selectivity, it is often necessary to adjust the pore structure of ACF or modify its surface characteristics. At present, the common modification methods mainly include surface oxidation and reduction, loading metals and metal oxides, microwave modification and so on(Qiu et al. 2018, Zhang et al. 2019). Studies have shown that due to the multi-functionality of metal oxides, after loading onto ACF, a great deal of binding sites can be provided, thereby greatly improving the adsorption performance of ACF(Chen et al. 2017, Zhang et al. 2016a).

The strong adsorption properties of ACF can not only enrich the target pollutants, capture intermediate toxic products and promote the photocatalytic performance of nano- $\mathrm{TiO}_{2}$, but also provide support for the renewable performance of $\mathrm{TiO}_{2}$ photocatalytic materials. Therefore, the preparation of bifunctional catalysts with adsorption and photocatalytic oxidation function has become a research hotspot in recent years(Popova et al. 2020). Nguyen et al. (Nguyen et al. 2020) fabricated magnesium-ammonia-claybased $\mathrm{TiO}_{2}$ supported on ACF $\left(\mathrm{MgAC}-\mathrm{TiO}_{2}\right)$ which used to eliminate methylene blue $(\mathrm{MB})$. The results revealed that the sintering of $\mathrm{TiO}_{2}$ was impeded due to the supplement of $\mathrm{MgAC}$, while ACF could further improved the photocatalytic activity by preventing electron-hole recombination. Liu et al. (Liu et al. 2010) explored the degradation performance of $\mathrm{FeO} / \mathrm{TiO}_{2} / \mathrm{ACF}$ composites for the degradation of 2,4dichlorophenol (2,4-DCP). The experimental data indicated that the removal efficiency of 2,4-DCP was promoted attributing to the adsorption of ACF, at the same time, the recombination of electron-hole pairs were prevented effectively by $\mathrm{Fe}$ loaded on $\mathrm{TiO}_{2} . \mathrm{TiO}_{2}$ irradiated by UV provided electrons to reduce $\mathrm{Fe}^{3+}$ and $\mathrm{Fe}^{2+}$ back to $\mathrm{FeO}$, which prevented the active loss of FeO. Jain et al. (Jain et al. 2019) loaded nano$\mathrm{TiO}_{2}$ on ACF by impregnation-hydrothermal method, and prepared $\mathrm{TiO}_{2} / \mathrm{ACF}$ composites, which were used to remove methylene blue $(\mathrm{MB})$ from wastewater under continuous flow conditions. The results showed that ACF played a dual role of adsorption and fixation of nano-TiO 2 . However, the study of $\mathrm{TiO}_{2}$ loading on ACF modified by zinc salt for VOCs removal is rarely reported.

Hence, in this study, activated carbon fibers (ACFs) were firstly modified with $\mathrm{Zn}\left(\mathrm{NO}_{3}\right)_{2}, \mathrm{ZnCl}_{2}$ and $\mathrm{Zn}\left(\mathrm{CH}_{3} \mathrm{COO}\right)_{2}$ ) respectively, by ultrasonic-vacuum impregnation method, subsequently, $\mathrm{TiO}_{2}$ was loaded on the modified ACF by ultrasonic-vacuum assisted sol-gel method (Fig. 1). After that, selecting toluene, which is representative of VOCs, as the target pollutant, and the composites were applied to eliminate toluene. The adsorption and photocatalytic performance of each composite was investigated in the selfdesigned reactor. Combined with the results of characterization and analysis, the $\mathrm{TiO}_{2} / \mathrm{ACF}^{-} \mathrm{Ac}$ catalyst with the best removal performance was selected. Subsequently, the removal efficiency of toluene by $\mathrm{TiO}_{2} / \mathrm{ACF}^{-}{ }_{\mathrm{Ac}}$ under different factors was investigated to determine the optimal reaction conditions. Various intermediate products and main reaction pathways were analyzed based on the results of GC- 
MS, and the synergistic mechanism of adsorption and photocatalysis removal for toluene removal on $\mathrm{TiO}_{2} /$ ACF- $^{-}$c was also explored.

\section{Materials And Methods}

\subsection{Materials}

Activated carbon fiber (ACF) was purchased from Nantong Senyou Carbon Fiber Co., Ltd. Concentrated nitric acid $\left(\mathrm{HNO}_{3}, 68 \%\right)$, zinc nitrate $\left(\mathrm{Zn}\left(\mathrm{NO}_{3}\right)_{2}, \mathrm{AR}\right)$, zinc acetate $\left(\mathrm{Zn}\left(\mathrm{CH}_{3} \mathrm{COO}\right)_{2}, \mathrm{AR}\right)$, zinc chloride $\left(\mathrm{ZnCl}_{2}\right.$, $A R)$, anhydrous ethanol $\left(\mathrm{C}_{2} \mathrm{H}_{6} \mathrm{O}, \mathrm{AR}\right)$, acetic acid $\left(\mathrm{CH}_{3} \mathrm{COOH}\right)$, tetrabutyl titanate $\left(\mathrm{C}_{6} \mathrm{H}_{36} \mathrm{O}_{4} \mathrm{Ti}, \mathrm{TBOT}, \mathrm{AR}\right)$ and carbon disulfide $\left(\mathrm{CS}_{2}, \mathrm{AR}\right)$ were supplied by Sinopharm Chemical Reagent Co., Ltd.

\subsubsection{Preparation of modified ACF materials}

Firstly, $\mathrm{Zn}\left(\mathrm{NO}_{3}\right)_{2}, \mathrm{ZnCl}_{2}$ and $\mathrm{Zn}\left(\mathrm{CH}_{3} \mathrm{COO}\right)_{2}$ solutions with the same mass concentration were prepared according to the standard of $\mathrm{Zn}$ concentration. Then, 10 pieces of ACFs were put into the prepared solution. The ACFs were immersed in vacuum chamber for 10 minutes after ultrasonic treatment. The ultrasonic-vacuum impregnation process was repeated twice to realize the full impregnation of ACF solution. Then the impregnated ACF was placed in an oven at $105^{\circ} \mathrm{C}$ for drying, and the products were sealed and preserved. ACF modified by zinc nitrate, zinc acetate and zinc chloride are denoted as $\mathrm{ACF}^{-}{ }_{\mathrm{Nc}}$, $\mathrm{ACF}^{-{ }_{\mathrm{AC}}}$ and $\mathrm{ACF}_{-\mathrm{HC}}$ respectively.

\subsubsection{Preparation of $\mathrm{TiO}_{2}$ composites supported on modified ACF}

With tetrabutyl titanate as the presoma of titanium dioxide, ACF-based photocatalytic composites were prepared by ultrasonic-vacuum-assisted sol-gel method. Anhydrous ethanol and acetic acid were mixed in a volume ratio of $2: 1$, then $10 \mathrm{~mL}$ of tetrabutyl titanate (TBOT) was added to the mixture, after that, the magnetic stirring last 30 minutes to obtain solution $A$. The solution $B$ contained mixing solution of $10 \mathrm{~mL}$ ethanol, $2 \mathrm{~mL}$ acetic acid and $30 \mathrm{~mL}$ deionized water was prepared under the condition of magnetic stirring. B solution was slowly added to A solution with intensive stirring. Subsequently, the stirring process lasted for 2 hours, and then aged for 24 hours at room condition. The modified ACFs with the shape of $20 \mathrm{~mm} \times 20 \mathrm{~mm}$ squares were put into the aged sol. Then, the mixture was immersed in a vacuum drying oven for 10 minutes after ultrasonication for 10 minutes, and the operation was repeated several times to achieve the compounding of materials. The impregnated composites were put into a kiln at $105^{\circ} \mathrm{C}$ for 2 hours, and then cooled slowly to ordinary temperature. The composites were prepared after calcining the cooled productions at $450^{\circ} \mathrm{C}$ for 2 hours in tube furnace, with $\mathrm{N}_{2}$ as protective gas and the heating rate was $50^{\circ} \mathrm{C} / \mathrm{min}$. $\mathrm{TiO}_{2} / \mathrm{ACF}_{-} \mathrm{Nc}, \mathrm{TiO}_{2} / \mathrm{ACF}^{-}{ }_{\mathrm{Ac}}$ and $\mathrm{TiO}_{2} / \mathrm{ACF}_{-}{ }_{\mathrm{Hc}}$ composites were prepared and reserved.

2.2 Characterization of the catalyst 
The crystalline phase and grain size of the composites were determined by X-ray diffraction spectra (XRD, PANalytical B.V., AXIOS-Petro) with power $2200 \mathrm{~W}$, Cu-Ka radiation $(\lambda=1.5406 \AA)$. The components and chemical bound information of the samples were characterized by Fourier transform infrared spectrometer (FTIR, Nicolet, Nexus). Scanning electron microscope (SEM, Hitachi, S4800) with scanning voltage $50 \mathrm{kV}$ was used to investigate the morphologies of the composites. X-ray photoelectron spectrometer (XPS, Thermo Scientific, K-Alpha) was employed to analyze the ultimate composition and valence state of the composites. The specific surface area and pore size of the samples were measured by the analysis of Brunauer-Emmett-Teller (BET, ASAP3020, Mike Instruments Co.). Adsorption was carried out at $77.4 \mathrm{~K}$ with $\mathrm{N}_{2}$ as adsorbate, and desorption occurred at $300 \mathrm{~K}$. Ultraviolet-visible diffuse reflectance spectrophotometer (UV-vis DRS, TU-1901, Beijing General Instrument Co.) were used to test the optical absorption properties of the composites. I-T photocurrent analysis can be used to determine the light response of materials. The working electrode is samples/conductive glass, the counter electrode is platinum wire, and the reference electrode is saturated calomel electrode. Under the bias voltage of $0.0 \mathrm{~V}$, the samples were irradiated by visible light with $300 \mathrm{~W}$ xenon lamp purchased from Beijing Perfect Light Source Research Institute, and the photocurrent test were investigated.

\subsection{Adsorption and phootocatalysis properties measurement}

The composites were cut into squares of $20 \mathrm{~mm} \times 20 \mathrm{~mm}$ and fixe in the quartz tube reactor, and then the self-assembly experimental device was operated without any pollutions to the stable airflow at room temperature and atmospheric pressure, and subsequently the dark reaction was carried out to make the composites fully absorb toluene with the initial concentration was $1000 \mathrm{mg} / \mathrm{m}^{3}$ and the flow rate was $120 \mathrm{~mL} / \mathrm{min}$. After reaching the adsorption equilibrium, the low pressure mercury lamp was turned on for photocatalytic reaction. During the experiment, activated carbon was used to sample the inlet and exit toluene at regular intervals. The samples were resolved with carbon disulfide and inject into the gas chromatography (GC, SP-3420A) to determine the strength of toluene. The degradation efficiency of gaseous toluene was calculated as follow:

$$
R=\frac{C_{0}-C}{C_{0}} \times 100 \%
$$

where $R$ is the removal efficiency, $C_{0}\left(\mathrm{mg} / \mathrm{m}^{3}\right)$ and $\mathrm{C}\left(\mathrm{mg} / \mathrm{m}^{3}\right)$ mean the concentration of toluene at the initial time and t time, respectively.

\section{Results And Discussion}

\subsection{Composition and structure characterization}

XRD is used to analyze the microstructure of the materials. The XRD patterns of samples are shown in Fig. 2(a). According to PDF card (JCPDS no21-1272)(Hou et al. 2012), the anatase phase characteristic diffraction peaks of $\mathrm{TiO}_{2}$ composites supported on modified ACFs with different zinc salts are observed 
at $2 \theta=2532^{\circ}, 3784^{\circ}, 4807^{\circ}, 5395^{\circ}, 5510^{\circ}$ and $6275^{\circ}$, corresponding to $101,004,200,105,211$ and 204 crystal planes, respectively. The XRD patterns of $\mathrm{ACF}^{-}{ }_{\mathrm{NC}}$ and $\mathrm{ACF}^{-}{ }_{\mathrm{Ac}}$ composites show the characteristic diffraction peaks of $\mathrm{ZnO}$ at $2 \theta=31.73^{\circ}(100), 34.36^{\circ}(002), 36.20^{\circ}(101), 47.47$ (102), 56.53 (110) and 66.29 (200), indicating that $\mathrm{ACF}_{-}{ }_{\mathrm{Nc}}$ decomposed into $\mathrm{ZnO}$ under $\mathrm{N}_{2}$ atmosphere calcination in tube furnace. However, the characteristic diffraction peak of $\mathrm{ZnO}$ disappear after loading $\mathrm{TiO}_{2}$, indicating that $\mathrm{Zn}$ ions do not exist in the form of $\mathrm{ZnO}$ alone during the preparation of $\mathrm{TiO}_{2}$.

As shown in Fig.2(b), which can fairly indicate nitrogen adsorption and desorption isotherms of $\mathrm{TiO}_{2} /$ ACF- ${ }_{\mathrm{Ac}}$ composites, the same curves could be found of all materials belonging to the type IV isotherm in the IUPAC adsorption isotherm(Zhang et al. 2016b). In the medium-high pressure region, due to the difference between the desorption vapor pressure and the saturation pressure in the adsorption process, the adsorption-desorption curves are inconsistent, and all the materials have $\mathrm{H} 4$ hysteresis loops (0.5 1.0), manifesting that there may exist irregular pore structure of the composites, further there is a mixture of micropores and mesopores (Zhao et al. 2012).

The appearance of mesopores may be due to the use of vacuum ultrasonic impregnation method to make $\mathrm{TiO}_{2}$ load to the pore interior, thus forming a variety of microporous and mesoporous channels, which lead to a big difference of specific surface area than before. Barrett-Emmett-Teller (BET) method was applied to calculate the specific surface area, and Barrett-Joyner-Halenda (BJH) methods were performed to test size and volume of pore. From Table 1, a negative correlation can be discovered between the specific area of $\mathrm{TiO}_{2} / \mathrm{ACF}^{-}{ }_{\mathrm{Ac}}$ and $\mathrm{Zn}\left(\mathrm{CH}_{3} \mathrm{COO}\right)_{2}$ concentration. This may due to the introduction of $\mathrm{Zn}\left(\mathrm{CH}_{3} \mathrm{COO}\right)_{2}$ into $\mathrm{TiO}_{2}$ is more likely to agglomerate in the calcination process, resulting in the increase of the grain size of the composites. On the contrary, the volume of pores and surface area decreased, thereby reducing the photocatalytic degradation efficiency(Anonymous 2014).

Table 1 Pore size, pore volume and specific surface area $\left(\mathrm{S}_{\mathrm{BET}}\right)$ of $\mathrm{TiO}_{2} / \mathrm{ACF}^{-} \mathrm{Ac}$ composites with different concentrations

\begin{tabular}{|llll|}
\hline Sample & Pore size/ $(\mathrm{nm})$ & Pore volume $/\left(\mathrm{cm}^{3} / \mathrm{g}^{1}\right)$ & $\mathrm{S}_{\mathrm{BET}} /\left(\mathrm{m}^{2} / \mathrm{g}^{1}\right)$ \\
\hline $0.01 \mathrm{~mol} / \mathrm{L}$ & 1.81 & 0.53 & 1163.61 \\
\hline $0.05 \mathrm{~mol} / \mathrm{L}$ & 1.80 & 0.50 & 1117.59 \\
\hline $0.10 \mathrm{~mol} / \mathrm{L}$ & 1.78 & 0.45 & 1008.74 \\
\hline
\end{tabular}

From infrared spectra of the samples (Fig. 2(c)), a peak of -OH stretching vibration appears at $3440 \mathrm{~cm}^{-1}$ in all materials. The narrow absorption peak at $1635 \mathrm{~cm}^{-1}$ presents the bending stretching vibration band of $\mathrm{O}-\mathrm{H}$ adsorbed on the sample surface in water. The characteristic stretching vibration peak at 700 500 $\mathrm{cm}^{-1}$ is observed thanks to the fluctuation of Ti-O-Ti bond(Wang et al. 2011). The peak of ACF at 1084 $\mathrm{cm}^{-1}$ is $\mathrm{C}-\mathrm{O}$ stretching vibration peak, and there is a characteristic absorption peak in each composites, 
which can be put down to the combination of $\mathrm{TiO}_{2}$ and $\mathrm{C}-\mathrm{O}$ bond to form $\mathrm{Ti}-\mathrm{O}-\mathrm{C}$ stretching vibration peak(Eleutério et al. 2020). In $\mathrm{TiO}_{2} / \mathrm{ACF}{ }_{\mathrm{Ac}}$ composites, the characteristic peaks of $1687 \sim 1512 \mathrm{~cm}^{-1}$ and $1468 \sim 1410 \mathrm{~cm}^{-1}$ are the results of dissymetrical stretching oscillation and balanced stretching oscillation of -COO-, respectively, indicating that there is a double tooth coordination structure(B et al. 2019). The absorption peaks at $672 \mathrm{~cm}^{-1}$ ions were $\mathrm{Zn}-\mathrm{O}$ vibration absorption peaks, indicating that $\mathrm{Zn}$ was successfully loaded on ACF.

\subsection{Morphology and surface properties}

From the SEM images of samples (Fig. 3), it can be seen that, for all materials, there are many irregularly arranged fiber bands in the activated carbon, for each fiber band, there exists a linear groove and ridge in wire direction. The macropores in fibers facilitate the adsorption capacity of oxygen and toluene gas, and they are also beneficial to the reduce of pressure drop, so that more small molecule gases are rapidly aggregated on the surface of $\mathrm{TiO}_{2}$ (Xiang et al. 2010). SEM images reveal that $\mathrm{TiO}_{2}$ has been successfully loaded on modified $\mathrm{ACF}$, but the morphology of $\mathrm{TiO}_{2}$ on different modified $\mathrm{ACF}$ is different. $\mathrm{TiO}_{2}$ on $\mathrm{TiO}_{2} / \mathrm{ACF}_{-} \mathrm{Hc}_{\mathrm{C}}$ composites are the most smooth and uniform. $\mathrm{TiO}_{2}$ on $\mathrm{TiO}_{2} / \mathrm{ACF}_{-}{ }_{\mathrm{Nc}}$ is relatively smooth and uniform, but $\mathrm{TiO}_{2}$ on $\mathrm{ACF}^{-}{ }_{\mathrm{Ac}}$ surface is relatively rough. This the number of micropores, mesopores and the specific area of the composites increase owing to this rough structure which improves the adsorption capacity of toluene. The rough structure also increases the contact area between $\mathrm{TiO}_{2}$ and toluene, which is conducive to promoting the photocatalytic reaction.

As shown in SEM images of ACF- ${ }^{A c}$ composites with different impregnation times (Fig. 3(d), 3(e) and 3(f), $\mathrm{TiO}_{2}$ agglomerates gradually with the increase of impregnation times, resulting in $\mathrm{TiO}_{2}$ loading on the surface of ACF in the form of particles. However, in the process of one impregnation, only local $\mathrm{TiO}_{2}$ is loaded on the ACF surface, and the loading of $\mathrm{TiO}_{2}$ is low, which is not conducive to the late photocatalytic reaction. Therefore, in this experiment, the material was impregnated twice.

\subsection{XPS analysis}

To precisely analyze the character of $\mathrm{TiO}_{2} / \mathrm{ACF}^{-}{ }_{\mathrm{Ac}}$ composites about its surface composition and valence state, all samples were tested by X-ray photoelectron spectroscopy. $\mathrm{TiO}_{2} / \mathrm{ACF}^{-}{ }_{\mathrm{Ac}}$ composites contain four elements: $\mathrm{Zn}, \mathrm{Ti}, \mathrm{O}$ and $\mathrm{C}$, indicating that the composites have been successfully prepared. The characteristic peaks in the XPS spectrum of Zn (Fig. 4(b)) with binding energy of $1023.1 \mathrm{eV}$ and 1046.4 $\mathrm{eV}$ are assigned to $\mathrm{Zn} 2 \mathrm{p}_{3 / 2}$ and $\mathrm{Zn} 2 \mathrm{p}_{1 / 2}$ respectively, indicating that $\mathrm{Zn}$ in $\mathrm{TiO}_{2} / \mathrm{ACF}^{-}{ }_{\mathrm{Ac}}$ composites exists in the form of +2 valence, which also indicates that the valence state of $Z n$ in the composites does not change during the preparation process(Lirong et al. 2009).

Analysis of existing research, the $\mathrm{O}_{2}$-ions in the oxygen vacancy of $\mathrm{Zn}$ matrix has some relation to the characteristic peak with binding energy of $531.6 \mathrm{eV}$ according to the $01 \mathrm{~s} \mathrm{spectra(Wang} \mathrm{et} \mathrm{al.} \mathrm{2018),} \mathrm{and}$ the characteristic peak with binding energy of $530.5 \mathrm{eV}$ corresponds to the lattice oxygen of $\mathrm{TiO}_{2}$, which 
further indicates the composites are successfully prepared(Li et al. 2019). In high resolution Ti2p spectra (Fig. 4(d)), two main complex peaks were observed at 459.3 and $464.9 \mathrm{eV}$, corresponding to $\mathrm{Ti}^{2} \mathrm{p}_{3 / 2}$ and $\mathrm{Ti}_{2} \mathrm{p}_{1 / 2}$ spin-orbit splitting photoelectrons of $\mathrm{Ti}^{4+}$, respectively(Zhang et al. 2016d). In the XPS spectra of C1s (Fig. 4(e)), the $C$ peak centered at $284.5 \mathrm{eV}$ represents the $\mathrm{C}-\mathrm{C}=\mathrm{C}$ bond. The presence of $\mathrm{C}-\mathrm{O}-\mathrm{R}$ such oxygenated carbon species is the genesis of $285.7 \mathrm{eV}$ peak. The peak at $289.0 \mathrm{eV}$ corresponds to the $\mathrm{C}=\mathrm{O}$ bond(Su-Il et al. 2016). It indicates that the composites contain carbon element and the modified ACFs are successfully synthesized. In summary, the XPS analysis results clearly confirms the formation of $\mathrm{TiO}_{2}$ /ACF-Ac composites, which supports the analysis results of XRD.

\subsection{Electrochemical and optical properties}

The UV-vis diffuse reflectance spectra and transient photocurrent response of samples were investigated to explore the optical properties. As shown in Fig. 5 (a), around the UV region with wavelength less than $380 \mathrm{~nm}, \mathrm{TiO}_{2} /$ ACF- $_{-\mathrm{Hc}}$ showed obvious band gap absorption peak, while in the non-UV region with wavelength greater than $400 \mathrm{~nm}$, there was almost no response. The reason for this phenomenon may be that the decomposition temperature of zinc salt during calcination is different, resulting in different crystallization time of $\mathrm{Zn}$ and $\mathrm{TiO}_{2}$ (Smirniotis et al. 2018). Both $\mathrm{TiO}_{2} / \mathrm{ACF}^{-}{ }_{\mathrm{Ac}}$ and $\mathrm{TiO}_{2} / \mathrm{ACF}^{-}{ }_{\mathrm{Nc}}$ composites have visible light feedback with wavelength greater than $400 \mathrm{~nm}$. This may be due to the fact that $\mathrm{Zn}$ ions enter the lattice of $\mathrm{TiO}_{2}$ to replace $\mathrm{O}$ atoms and form a new doped energy level, thereby reducing the band gap and widening the optical absorption range of $\mathrm{TiO}_{2}$ that accords with the test results XPS. By comparison with $\mathrm{TiO}_{2} / \mathrm{ACF}_{-}{ }_{\mathrm{Nc}}, \mathrm{TiO}_{2} / \mathrm{ACF}_{-} \mathrm{Ac}$ has a wider range of visible light response wavelength, showing more excellent photocatalytic performance. Fig. 5 (b) shows the photocurrent curve within $20 \mathrm{~s}$ under the bias voltage of $0.0 \mathrm{~V}$ and $0.1 \mathrm{M} \mathrm{NaSO} 4$ solution as the electrolyte. After three cycles, the photocurrents still had good reproducibility, indicating that the samples had good stability. Compared with other samples, the $\mathrm{TiO}_{2} /$-ACF- ${ }^{-}$c sample has higher photocurrent intensity, suggesting that its photogenerated electrons and holes separation efficiency is more-efficient, which make some works to the enhancement of photocatalytic performance.

\subsection{Optimum selection of composites}

In order to select the composites with the best performance among $\mathrm{TiO}_{2}$ supported on modified ACFs with different zinc salts, the toluene removal performances with the same conditions are tested. The photocatalysis property and adsorption capacity of toluene by different composites are shown in Fig. 6 . Fig. 6(a) shows that $\mathrm{TiO}_{2} / \mathrm{ACF}^{-}{ }_{\mathrm{Ac}}$ composites have the longest adsorption saturation time (21 hours) and the largest adsorption capacity (151.2 $\mathrm{mg} /$ layer), realizing a greater level of concentration of toluene gas and increasing the concentration of reactants, which is conducive to the subsequent photocatalytic reaction and extending the residence time of toluene on $\mathrm{ACF}$. It can be seen from Fig. $6\left(\mathrm{a}^{\prime}\right)$ that $\mathrm{TiO}_{2} / \mathrm{ACF}$ Ac composites have the highest photocatalytic efficiency (70\%) for toluene. These results reveal that the $\mathrm{TiO}_{2} / \mathrm{ACF}^{-}{ }_{\mathrm{Ac}}$ realizes the dual optimization of adsorption and photocatalytic. Hence, the $\mathrm{TiO}_{2} / \mathrm{ACF}^{-} \mathrm{Ac}$ 
composites with the highest toluene adsorption and photocatalytic performance are selected for the subsequent experimental studies.

\subsection{Removal performance of toluene on $\mathrm{TiO}_{2} / \mathrm{ACF}^{-} \mathrm{Ac}$}

The effect of concentration of $\mathrm{Zn}\left(\mathrm{CH}_{3} \mathrm{COO}\right)_{2}$ on $\mathrm{TiO}_{2} / \mathrm{ACF}^{-}{ }_{\mathrm{Ac}}$ for toluene removal are shown in Fig. 7(a) and (a'). Compared with bare $\mathrm{TiO}_{2} / \mathrm{ACF}, \mathrm{Fig}$. 7(a) shows that the adsorption saturation time of $\mathrm{Zn}\left(\mathrm{CH}_{3} \mathrm{COO}\right)_{2}$ modified materials are longer, and the adsorption equilibrium time of $\mathrm{TiO}_{2} / \mathrm{ACF}^{-} \mathrm{Ac}$ composites is up to 40 hours. Moreover, with the increase of $\mathrm{Zn}\left(\mathrm{CH}_{3} \mathrm{COO}\right)_{2}$ concentration, the adsorption capacity and photocatalytic properties of $\mathrm{TiO}_{2} / \mathrm{ACF}^{-}{ }_{\mathrm{Ac}}$ gradually decrease due to the destructions of the microporous structure and adsorption sites of the composites caused by too much modified solution ions, indicating that a small amount of $\mathrm{Zn}\left(\mathrm{CH}_{3} \mathrm{COO}\right)_{2}$ doping is more conducive to the adsorption and photocatalytic of $\mathrm{TiO}_{2} / \mathrm{ACF}^{-}{ }_{\mathrm{Ac}}$ for toluene.

Calcination temperature affects the adsorption and photocatalytic properties of composites by affecting the texture properties and crystallinity(Aristanti et al. 2019). As shown in Fig. 7(b), under different calcination temperatures, the adsorption saturation time of toluene on $\mathrm{TiO}_{2} / \mathrm{ACF}^{-}{ }_{\mathrm{Ac}}$ composites are different. The adsorption saturation time at $400,450^{\circ} \mathrm{C}, 500^{\circ} \mathrm{C}$ and $550^{\circ} \mathrm{C}$ is $17,40,9$ and $8 \mathrm{~h}$, respectively. As shown in Fig. $7\left(b^{\prime}\right)$, when the temperature of calcination is lower than $450^{\circ} \mathrm{C}$, the photocatalytic efficiency of $\mathrm{TiO}_{2} / \mathrm{ACF}^{-}{ }_{\mathrm{Ac}}$ increases with the rise of temperature; On contrast, the photocatalytic efficiency will go down with the continuing rise of temperature. $450^{\circ} \mathrm{C}$ is the position of highest removal efficiency. When the calcination temperature exceeds $450^{\circ} \mathrm{C}$, the increase of temperature will change the type and amount of oxygen-containing functional groups on the surface of the composites, and reduce the adsorption sites, thereby reduce the adsorption performance of $\mathrm{TiO}_{2} / \mathrm{ACF}^{-}{ }_{\mathrm{Ac}}$ composites for toluene(Sun et al. 2015). At the same time, $\mathrm{TiO}_{2}$ gradually transforms from anatase phase to rutile phase with the increase of calcination temperature, and the anatase content produced at $450^{\circ} \mathrm{C}$ is the maximal. The dislocation of defects in anatase lattice can produce oxygen vacancies that promote electron-hole separation, and increase the photocatalytic performance of $\mathrm{TiO}_{2} / \mathrm{ACF}_{-} \mathrm{Ac}(\mathrm{Horti}$ et al. 2019). As the temperature of calcination rise without interruption, the grain of $\mathrm{TiO}_{2}$ gradually grows, and the phenomenon of sintering or even channel collapse or blockage occurs that eventually change the character of composites specific surface area and catalytic activity, making these performance reduce (Zhang et al. 2016c).

The performance of toluene removal by $\mathrm{TiO}_{2} / \mathrm{ACF}^{-}{ }_{\mathrm{Ac}}$ with change of impregnation times are shown in Fig. 7(c) and ( $\left.c^{\prime}\right)$. With the increase of impregnation times, the adsorption capacity and photocatalytic activity of $\mathrm{TiO}_{2} / \mathrm{ACF}_{-} \mathrm{Ac}$ for toluene first increase and then decrease. The saturation adsorption time of $\mathrm{TiO}_{2} / \mathrm{ACF}-$ Ac composites with once, twice and three impregnation times is 31,40 and 12 hours respectively. Combined with the analysis of SEM results, it is obviously that the morphologies of the samples is modified by zinc ion doping, which can make the $\mathrm{TiO}_{2}$ loaded on ACF present a rough and porous morphology, thereby improving the adsorption capacity. The loading amount of $\mathrm{TiO}_{2}$ increases as coating 
times rise, which promotes the improvement of photocatalytic performance. However, when the loading amount is too high, $\mathrm{TiO}_{2}$ would agglomerate and could not be uniformly loaded on the surface of $\mathrm{ACF}$, which reduces the contact area between $\mathrm{TiO}_{2}$ and toluene and the number of active sites, thereby reducing the removal efficiency of toluene.

The effect of relative humidity $(40 \%, 60 \%, 80 \%)$ on toluene removal by $\mathrm{TiO}_{2} / \mathrm{ACF}{ }_{\mathrm{Ac}}$ composites are shown in the Fig. $7(d)$ and (d'). As the index of relative humidity was increased, $\mathrm{TiO}_{2} / \mathrm{ACF}^{-}{ }_{\mathrm{Ac}}$ character of adsorption capacity for toluene decreases, while the photocatalytic performance increases instead. This is because exorbitant relative humidity will bring excessive vapor molecules which will occupy the adsorption sites of the composites, reducing the contact area between toluene and $\mathrm{TiO}_{2} / \mathrm{ACF}{ }_{\mathrm{Ac}}$. In addition, toluene is hydrophobic, when the adsorption sites are occupied by water vapor, toluene can only flow with air, thus reducing the adsorption effect of composites on toluene(Lin et al. 2013). However, increasing water vapor can accelerate the production of hydroxyl radicals $(\cdot \mathrm{OH})$ that is of vital importance for photocatalytic reaction, and the oxidation of toluene can be decomposed into non-toxic and harmless substances to achieve harmless treatment. Therefore, relative humidity plays a dual role in toluene removal(Ho et al. 2019).

The effect of different stacking layers for toluene removal are shown in the Fig. 7(e) and (e'). The stacking method of the materials is as follows: one layer of material is placed in the center of the reactor, when the second layer is placed, the distance between the two composites is $2 \mathrm{~cm}$, and the distance between each two pieces of the three layers is $2 \mathrm{~cm}$. The adsorption saturation time of toluene was 15,33 and $50 \mathrm{~h}$ with the layers of the composites were one layer, two layers and three layers, respectively, moreover, the adsorption and the photocatalytic efficiency are improved. With the increase of the stacking layers, the cavities between the layers of the composites and the resistance of toluene molecules increase when passing through the composites prolong the residence time of toluene, which can not only improve the adsorption efficiency, but also enable the intermediate products to react further, and realize the complete catalytic oxidation of toluene. In addition, the cavities between layers increase the retention time of toluene and prolonged the adsorption saturation time and also makes the composites more fully use of light and improve the photocatalytic removal efficiency of toluene.

Ultraviolet light intensity can directly affect the generation of photogenerated electrons, thereby affecting the photocatalytic activity of composites. The effect of different UV light intensity (8W, 16W, 24W) for toluene removal on $\mathrm{TiO}_{2} / \mathrm{ACF}_{\mathrm{Ac}}$ composites is studied and showed in Fig. 7(f'). With the increase of light intensity, the absorbability and photocatalytic performance of $\mathrm{TiO}_{2} / \mathrm{ACF}^{-} \mathrm{Ac}$ for toluene increases. The stronger the light intensity, the more photogenerated electrons and holes excited, the more strong oxidizing free radicals generated, the higher the toluene removal rate(He et al. 2019). However, the light intensity is not proportional to the toluene removal rate, it is mainly because the stronger intensity of UV light can result in the more obvious thermal effect which is not unfavorable to the adsorption of toluene. However, the desorption rate of toluene from $\mathrm{TiO}_{2} / \mathrm{ACF}^{-}{ }_{\mathrm{Ac}}$ caused by the thermal effect is lower than the 
synergistic rate of adsorption-photodegradation. The overall performance is that the toluene removal rate increases with the increase of light intensity(Dilla et al. 2017).

The reacted composites are calcined in a tubular oven at $450^{\circ} \mathrm{C}$ to explore its cycle performance. The relationship between the number of cycles and removal efficiency is shown in Fig. 7(g'). After three cycles of test, the removal efficiency of toluene still maintains at about $70 \%$, indicating that $\mathrm{TiO}_{2} / \mathrm{ACF}^{-} \mathrm{Ac}$ composites have good cycle stability, and the slight decrease may be due to the regeneration process do not completely release the adsorption sites and photocatalytic activity sites of the materials.

\subsection{Mechanism analysis of toluene removal by $\mathrm{TiO}_{2} / \mathrm{ACF}^{-}{ }_{\mathrm{Ac}}$ composites}

Combined with the research content, the synergistic mechanism of adsorption and photodegradation for toluene removal by $\mathrm{TiO}_{2} / \mathrm{ACF}^{-}{ }_{\mathrm{Ac}}$ composites is shown in Fig. 8 and the Eqs. (1)-(7). The doping of $\mathrm{Zn}\left(\mathrm{CH}_{3} \mathrm{COO}\right)_{2}$ make $\mathrm{TiO}_{2}$ load on the surface of ACF in a rough form, increases the contact area with toluene, also it modifies the adsorption character of $\mathrm{TiO}_{2} / \mathrm{ACF}^{-}{ }_{\mathrm{Ac}}$ to toluene. Toluene is converted into $\mathrm{CO}_{2}, \mathrm{H}_{2} \mathrm{O}$ and other intermediates via chemical reaction, which promotes the toluene captured by $\mathrm{TiO}_{2} / \mathrm{ACF}^{-}$Ac to transfer to the superficies of $\mathrm{TiO}_{2}$ for the next reaction(Balbayeva et al. 2018). ACF has good electronic conductivity and can transfer photogenerated $\mathrm{e}^{-}$and $\mathrm{h}^{+}$to the electron acceptor through the interface charge transfer, and the large pores between ACF fibers can reduce the mass transfer limitation and accelerate the flow of toluene among them.

$\mathrm{TiO}_{2}$ produces photogenerated $\mathrm{e}^{-}$and $\mathrm{h}^{+}$under the excitation of ultraviolet light, and reacts with $\mathrm{O}_{2},-\mathrm{OH}$ and $\mathrm{H}_{2} \mathrm{O}$ on the surface to generate hydroxyl radicals and superoxide radicals( $\mathrm{Li}$ et al. 2020b). The toluene molecules which were adsorbed will react with hydroxyl radicals and superoxide radicals and be transformed to $\mathrm{CO}_{2}, \mathrm{H}_{2} \mathrm{O}$ and other intermediates(Reddy et al. 2015). Moreover, the generated small molecule substances such as $\mathrm{H}_{2} \mathrm{O}, \mathrm{CO}_{2}$ and others can be directly desorbed from the surface of the composites, which can achieve the in-situ regeneration of the adsorbent.

$$
\begin{aligned}
& \mathrm{TiO}_{2}+h v \rightarrow e^{-+}+h^{+} \\
& \mathrm{O}_{2}+\mathrm{e}^{-} \rightarrow \cdot \mathrm{O}_{2}^{-} \\
& \mathrm{H}_{2} \mathrm{O}+\mathrm{h}^{+} \rightarrow \cdot \mathrm{OH}+\mathrm{H}^{+}
\end{aligned}
$$$$
\mathrm{OH}^{-}(\text {surface })+\mathrm{h}^{+} \rightarrow \cdot \mathrm{OH}
$$$$
\text { Toluene }+\cdot \mathrm{O}_{2}^{-} \rightarrow \text { products }
$$$$
\text { Toluene+. } \mathrm{OH} \rightarrow \text { products }
$$

Toluene $+\mathrm{H}^{+} \rightarrow$ products 


\subsection{Analysis of intermediate products}

To further study the reaction process of photocatalytic degradation of toluene, a certain volume of export gas samples was collected and analyzed by SCION SQ GC-MS. The test results indicate that the main intermediate products of toluene photodegradation were benzene $\left(\mathrm{C}_{6} \mathrm{H}_{6}\right)$, phenol $\left(\mathrm{C}_{6} \mathrm{H}_{6} \mathrm{O}\right)$, benzaldehyde $\left(\mathrm{C}_{7} \mathrm{H}_{6} \mathrm{O}\right)$, and hexane $\left(\mathrm{C}_{6} \mathrm{H}_{14}\right)$. The main reaction pathways of toluene photodegradation are proposed in Fig. 9. Under the irradiation of ultraviolet lamp, the photogenerated electrons and hydroxyl radicals are generated, which act on the methyl of toluene to dehydrogenate and generate hydrogen radicals $(\mathrm{H} \cdot)$ and benzyl radicals $\left(\mathrm{PhCH}_{2}\right)$ that further react with $\mathrm{O}_{2}$ in the system to generate benzyl peroxy radicals $\left(\mathrm{PhCH}_{2} \mathrm{O} \cdot\right)$. The coupling product of $\mathrm{PhCH}_{2} \mathrm{O}_{2}$ is unstable and decomposes to benzyl alcohol that continue to be oxidized to form benzaldehyde(Feng et al. 2019). Phenol is produced when methyl groups on toluene are substituted by hydroxyl radicals. The substituted methyl and benzyl generate phenylacetaldehyde under the action of free radicals, and phenylacetaldehyde is further oxidized to phenylacetic acid under the synergistic effect of ultraviolet light and $\mathrm{O}_{2}$. After absorbing certain photons, toluene will undergo splitting and isomerization reactions to produce long-chain products, such as hexane.

\section{Conclusion}

(1) $\mathrm{TiO}_{2} / \mathrm{ACF}^{-} \mathrm{Nc}, \mathrm{TiO}_{2} / \mathrm{ACF}_{-} \mathrm{Hc}_{\mathrm{H}}$ and $\mathrm{TiO}_{2} / \mathrm{ACF}^{-}{ }_{\mathrm{Ac}}$ were successfully prepared by ultrasonic-assisted sol-gel method. Through the analysis of the crystal structure, morphology, optical properties of the composites and the removal performance of toluene under the same conditions, the $\mathrm{TiO}_{2} / \mathrm{ACF}^{-}{ }_{\mathrm{Ac}}$ composites with the highest toluene adsorption and photocatalytic performance were selected for subsequent experimental studies.

(2) The characterization results of $\mathrm{TiO}_{2} / \mathrm{ACF}^{-} \mathrm{Ac}$ indicated that $\mathrm{TiO}_{2}$ with anatase phase was successfully loaded on ACF modified by $\mathrm{Zn}\left(\mathrm{CH}_{3} \mathrm{COO}\right)_{2}$, and composites with rough surface were prepared. $\mathrm{TiO}_{2} / \mathrm{ACF}-$ $\mathrm{AC}_{\mathrm{C}}$ composites contain large amount of oxygen-containing functional groups which are beneficial to the adsorption and photocatalytic oxidation of toluene. The results of optical properties showed that the modified ACF significantly improve the utilization efficiency of sunlight increasing the efficiency of charge transfer and separation of electron-hole pairs.

(3) When $\mathrm{TiO}_{2} / \mathrm{ACF}_{-}$Ac was calcined at $450^{\circ} \mathrm{C}$ and impregnated twice, the toluene inlet concentration, the gas flow and the light intensity of this system was $1000 \mathrm{mg} / \mathrm{m}^{3}, 120 \mathrm{~mL} / \mathrm{min}$ and $24 \mathrm{~W}$, respectively, the adsorption saturation time reached 40 hours and photodegradation rate was $70 \%$. As the index of relative humidity rises, the adsorption performance of $\mathrm{TiO}_{2} / \mathrm{ACF}^{-} \mathrm{Ac}$ decrease significantly, while the photocatalytic performance increase remarkably.

(4) The toluene removal rate of $\mathrm{TiO}_{2} / \mathrm{ACF}^{-}{ }_{\mathrm{Ac}}$ composites are positively correlated with the light intensity and the stacking layers of catalysts. After three cycle performance tests, $\mathrm{TiO}_{2} / \mathrm{ACF}^{-}{ }_{\mathrm{Ac}}$ still had high 
toluene removal efficiency, indicating that the composites had good cycle performance.

\section{Declarations}

Ethics approval and consent to participate

Not applicable

Consent for publication

Not applicable

Availability of data and materials

The datasets used and/or analysed during the current study are available from the corresponding author on reasonable request.

Competing interest

The authors declare that they have no known competing financial interests or personal relationships that could have appeared to influence the work reported in this paper.

Funding

This work was supported by Sinopec funded science and technology project (320039/YG2010).

Acknowledgements

My deepest gratitude goes first and foremost to professor Fang Liu, for her constant encouragement and guidance. I am indebted to professor Chaocheng Zhao owing to his guidance in this manuscript. And I also thank other authors for their contributions to the manuscript.

Authors' contributions

All authors contributed to the study conception and design. Material preparation, data collection and analysis were performed by Yuxi Bi and Encheng Sun. The first draft of the manuscript was written by Yuxi Bi and was checked by Encheng Sun and Shuai Zhang. The logic and grammar of the manuscript were examined by Fang Liu and Chaocheng Zhao. The spelling and references information of the manuscript were checked by Feiran Du and Haidi Wei. All authors commented on previous versions of the manuscript. All authors read and approved the final manuscript.

\section{References}

Anonymous (2014): Composites of small Ag clusters confined in the channels of well-ordered mesoporous anatase $\mathrm{TiO} 2$ and their excellent solar-light-driven photocatalytic performance. Nano 
Aristanti Y, Supriyatna YI, Masduki NP, Soepriyanto S (2019): Effect of calcination temperature on the characteristics of $\mathrm{TiO} 2$ synthesized from ilmenite and its applications for photocatalysis. IOP Conf. Ser.: Mater. Sci. Eng. 478, 012019

B XSA, B ZB, B YH, C HW, A FL, A SY (2019): Zn-Acetate-Containing ionic liquid as highly active catalyst for fast and mild methanolysis of Poly(lactic acid). Polym. Degrad. Stab. 168, 108937-

Balbayeva G, Yerkinova A, Inglezakis VJ, Poulopoulos SG (2018): Photochemical Degradation of Organic Pollutants in Wastewaters. IOP Conf. Ser.: Mater. Sci. Eng. 301, 012099

Behnam MA, Emami F, Sobhani Z, Dehghanian A (2018): The application of titanium dioxide (TiO2) nanoparticles in the photo-thermal therapy of melanoma cancer model. Iran. J. Basic Med. Sci. 21, 11331139

Chen, Huiyun, Yin, Qiong, Hengpeng, Dongyun, Kangle, Jinlin, Jia. (2017): Microwave-assisted rapid synthesis of Mn304/ACF hybrid for high efficient As(V) removal. Chem. Eng. Res. Des. 121, 431-437

Cheng Z, Feng K, Su Y, Ye J, Chen D, Zhang S, Zhang X, Dionysiou DD (2020): Novel biosorbents synthesized from fungal and bacterial biomass and their applications in the adsorption of volatile organic compounds. Bioresour. Technol. 300, 122705

Dilla, Martin, Mateblowski, Alina, Ristig, Simon, Strunk, Jennifer. (2017): Photocatalytic CO2 Reduction under Continuous Flow High-Purity Conditions: Influence of Light Intensity and $\mathrm{H} 2 \mathrm{O}$ Concentration. ChemCatChem 9, 4345-4352

Eleutério T, Sério S, Teodoro OMND, Bundaleski N, Vasconcelos HC (2020): XPS and FTIR studies of DC reactive magnetron sputtered $\mathrm{TiO} 2$ thin films on natural based-cellulose fibers. Coatings 10, 287

Fan M, He G, Zhou M (2020): The winter choke: Coal-Fired heating, air pollution, and mortality in China. J. Health Econ. 71, 102316

Feizpour F, Jafarpour M, Rezaeifard A (2019): Band Gap Modification of TiO2 Nanoparticles by Ascorbic Acid-Stabilized Pd Nanoparticles for Photocatalytic Suzuki-Miyaura and Ullmann Coupling Reactions. Catal. Lett. 149, 1595-1610

Feng B, Sun C, Zhang S (2019): Atmospheric degradation mechanism of benzyl peroxy radical: A theoretical study. Atmos. Environ. 201, 18-27

He L, Dong Y, Zheng Y, Jia Q, Shan S, Zhang Y (2019): A novel magnetic MIL-101(Fe)/TiO_2 composite for photo degradation of tetracycline under solar light. J. Hazard. Mater. 361, 85-94 
Hendry JR, Lee JGM, Battrum MJ (2019): CFD Model of Fluid Flow and Particle Deposition during Cryogenic Condensation. Chem. Eng. Res. Des. 143, 201-214

Ho C-C, Kang F, Chang G-M, You S-J, Wang Y-F (2019): Application of recycled lanthanum-doped TiO2 immobilized on commercial air filter for visible-light photocatalytic degradation of acetone and NO. Appl. Surf. Sci. 465, 31-40

Horti NC, Kamatagi MD, Patil NR, Nataraj SK, Sannaikar MS, Inamdar SR (2019): Synthesis and photoluminescence properties of titanium oxide (TiO2) nanoparticles: Effect of calcination temperature. Optik 194, 163070

Hou J, Yang X, Lv X, Huang M, Wang Q, Wang J (2012): Controlled synthesis of TiO2 mesoporous microspheres via chemical vapor deposition. J. Alloy. Compd. 511, 202-208

Jain P, Kumar A, Verma N, Gupta RK (2019): In-situ synthesis of TiO_2 nanoparticles in ACF:

Photocatalytic degradation under continuous flow. Solar Energy 189, 35-44

Lelicińska-Serafin K, Rolewicz-Kalińska A, Manczarski P (2019): VOC Removal Performance of a Joint Process Coupling Biofiltration and Membrane-Filtration Treating Food Industry Waste Gas. Int. J. Environ. Res. Public Health 16, 3009

Li J, Zhou YH, Zhong DY, Zhang JH (2019): Fluorine-controlled subgap states and negative bias illumination stability behavior in solution-processed InZnOF thin-film transistor. Appl. Phys. A 125, 527

Li Y, Liu F, Li M, Li W, Qi X, Xue M, Wang Y, Han F (2020a): Study on adsorption coupling photodegradation on hierarchical nanostructured g-C $3 \mathrm{~N} 4$ / TiO 2 /activated carbon fiber composites for toluene removal. J. Sol-Gel Sci. Technol. 93, 402-418

Li Y, Liu F, Li M, Wang X, Han F (2020b): Synergetic effect between adsorption and photodegradation on rGO/TiO2/ACF composites for dynamic toluene gaseous removal. Environ. Sci. Pollut. Res. 27, 98669881

Lin L, Chai Y, Zhao B, Wei W, He D, He B, Tang Q (2013): Photocatalytic oxidation for degradation of VOCs. Open J. Inorg. Chem. 03, 14-25

Lirong, Zheng, Yuanhui, Zheng, Chongqi, Chen, Yingying, Zhan, Xingyi, Lin (2009): Network Structured SnO2/ZnO Heterojunction Nanocatalyst with High Photocatalytic Activity. Inorg. Chem. 48, 1819-1825

Liu H, Yu Y, Shao Q, Long C (2019): Porous polymeric resin for adsorbing low concentration of VOCs: Unveiling adsorption mechanism and effect of VOCs' molecular properties. Sep. Purif. Technol. 228, 115755

Liu L, Chen F, Yang F (2010): Stable photocatalytic activity of immobilized Fe0/TiO2/ACF on composite membrane in degradation of 2,4-dichlorophenol. Sep. Purif. Technol. 70, 173-178 
Liu RF, Li WB, Peng AY (2018): A facile preparation of TiO2/ACF with CTi bond and abundant hydroxyls and its enhanced photocatalytic activity for formaldehyde removal. Appl. Surf. Sci. 427, 608-616

Miranda Zoppas F, Beltrame TF, Agustina Sosa F, Bernardes AM, Miro E, Albana Marchesini F (2020): Superficial properties of activated carbon fiber catalysts produced by green synthesis and their application in water purification. Environ. Sci. Pollut. Res. 27, 40405-40420

Mok YS, Kim S-G, Han J, Nguyen DB, Lee HW, Jeon H, Kim SB (2020): Removal of dilute ethylene using repetitive cycles of adsorption and plasma-catalytic oxidation over Pd/ZSM-5 catalyst. J. Phys. D: Appl. Phys. 53, 334002

Nguyen TN, Tran VV, Bui VKH, Kim M, Park D, Hur J, Kim IT, Lee HU, Ko S, Lee YC (2020): A Novel Photocatalyst Composite of Magnesium Aminoclay and TiO2 Immobilized into Activated Carbon Fiber (ACF) Matrix for Pollutant Removal. J. Nanosci. Nanotechnol. 20, 6844-6849

Popova M, Boycheva S, Lazarova H, Zgureva D, Lázár K, Szegedi Á (2020): VOC oxidation and CO2 adsorption on dual adsorption/catalytic system based on fly ash zeolites. Catal. Today $357,518-525$

Qiu W, Kang D, Ying Z, Huang H, Chen Y, Lu H (2018): Hierarchical pore structure of activated carbon fabricated by CO_2/microwave for volatile organic compounds adsorption. Chin. J. Chem. Eng. 26, 81-88 Qun, Zhao, Yingjie, Li, Xiaolong, Chai, Linzhen, Xu, Linfeng, Zhang (2019): Interaction of inhalable volatile organic compounds and pulmonary surfactant: Potential hazards of VOCs exposure to lung. J. Hazard. Mater. 369, 512-520

Reddy DA, Lee S, Choi J, Park S, Ma R, Yang H, Kim TK (2015): Green synthesis of Agl-reduced graphene oxide nanocomposites: Toward enhanced visible-light photocatalytic activity for organic dye removal. Appl. Surf. Sci. 341, 175-184

Smirniotis PG, Boningari T, Damma D, Inturi SNR (2018): Single-step rapid aerosol synthesis of N-doped TiO 2 for enhanced visible light photocatalytic activity. Catal. Commun. 113, 1-5

Su-II, Razzaq, Abdul, Grimes, Craig, A. (2016): Facile fabrication of a noble metal-free photocatalyst: TiO2 nanotube arrays covered with reduced graphene oxide. Carbon 98, 537-544

Sun Q, Hu X, Zheng S, Sun Z, Liu S, Li H (2015): Influence of calcination temperature on the structural, adsorption and photocatalytic properties of $\mathrm{TiO} 2$ nanoparticles supported on natural zeolite. Powder Technol. 274, 88-97

Tong R, Zhang L, Yang X, Liu J, Zhou P, Li J (2019): Emission characteristics and probabilistic health risk of volatile organic compounds from solvents in wooden furniture manufacturing. J. Clean Prod. 208, 1096-1108 
Wang C, Mao H, Wang C, Fu S (2011): Dispersibility and Hydrophobicity Analysis of Titanium Dioxide Nanoparticles Grafted with Silane Coupling Agent. Ind. Eng. Chem. Res. 50, 11930-11934

Wang XT, Ning XB, Shao Q, Ge SS, Fei ZY, Lei J, Hou BR (2018): ZnFeAl-layered double hydroxides/TiOcomposites as photoanodes for photocathodic protection of 304 stainless steel. Sci Rep 8,4116

Weon S, Choi J, Park T, Choi W (2017): Freestanding Doubly Open-ended TiO2 Nanotubes for Efficient Photocatalytic Degradation of Volatile Organic Compounds. Appl. Catal. B-Environ. 205, 386-392

Wu, Juan, Sun, Yuying, Gu, Chunhao, Wang, Ting, Xin, Yanjun (2018): Pt supported and carbon coated Bi2MoO6 composite for enhanced 2, 4-dibromophenol degradation under visible-light irradiation: Insight into band gap structure and photocatalytic mechanism. Appl. Catal. B-Environ. 237, 622-632

Xiang Q, Yu J, Cheng B, Ong HC (2010): Microwave-hydrothermal preparation and visible-light photoactivity of plasmonic photocatalyst Ag-TiO2 nanocomposite hollow spheres. Chem.-Asian J. 5, 1466-1474

Zhang L, Li M, Gao Y, Liu J, Xu Y (2016a): Performance and mechanism study on phosphate adsorption onto activated carbon fiber loading lanthanum and iron oxides. Desalin. Water Treat. 57, 4671-4680

Zhang L, Peng Y, Zhang J, Chen L, Meng X, Xiao FS (2016b): Adsorptive and catalytic properties in the removal of volatile organic compounds over zeolite-based materials. Chin. J. Catal. 37, 800-809

Zhang W, Pei X, Yang B, He H (2016c): Effects of Boron Content and Calcination Temperature on Properties of B-TiO2 Photocatalyst Prepared by Solvothermal Method. J. Adv. Oxid. Technol. 17, 66-72

Zhang W, Xiao X, Zeng X, Li Y, Zheng L, Wan C (2016d): Enhanced photocatalytic activity of TiO2 nanoparticles using SnS2/RGO hybrid as co-catalyst: DFT study and photocatalytic mechanism. J. Alloy. Compd. 685, 774-783

Zhang X, Yang J, Du Y (2019): Desulfurization performance of activated carbon fiber after oxidation modification. Chem. Ind. Eng. Prog. 38, 5151-5157

Zhao S, Chen S, Yu H, Quan X (2012): g-C3N4/TiO2 hybrid photocatalyst with wide absorption wavelength range and effective photogenerated charge separation. Sep. Purif. Technol. 99, 50-54

\section{Figures}




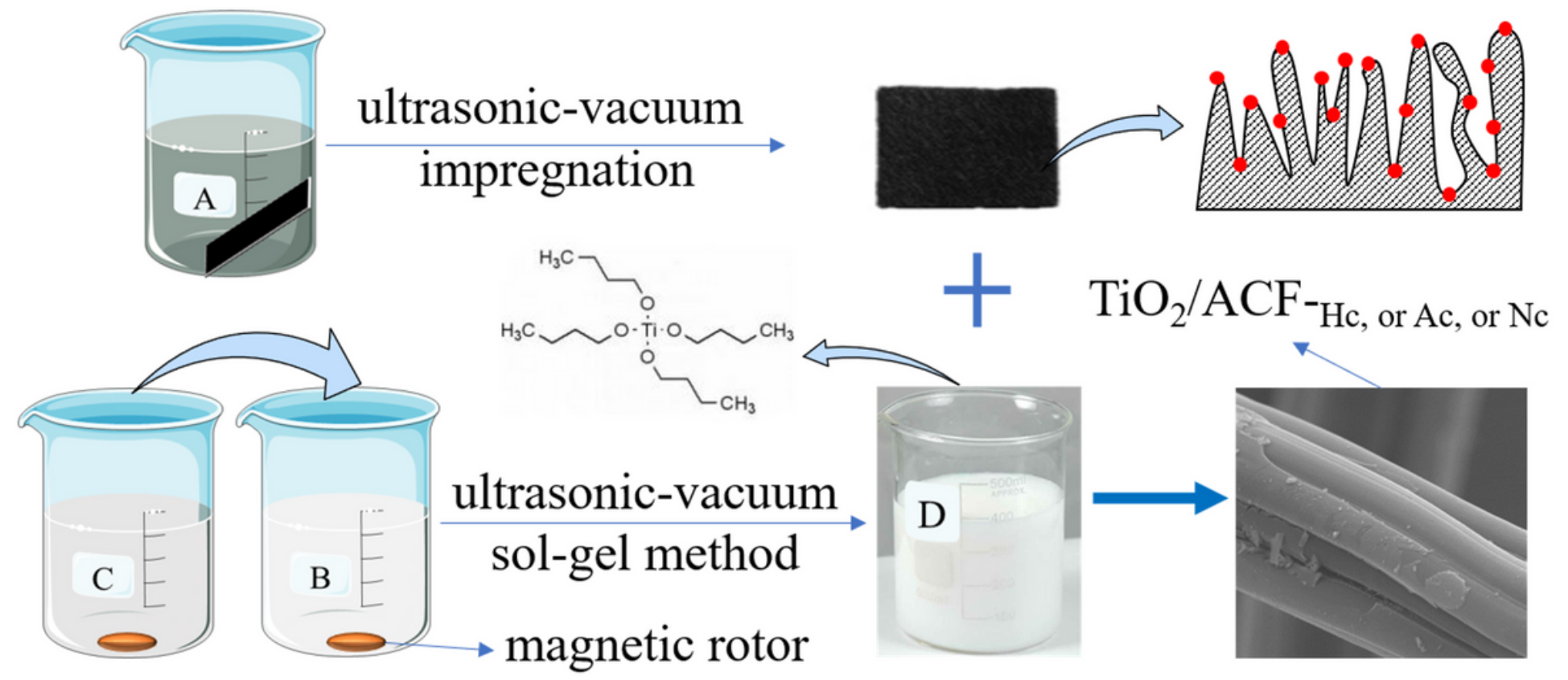

Figure 1

Schematic illustration of the synthetic processes of samples. Note: A: $\mathrm{Zn}(\mathrm{NO} 3) 2$ or $\mathrm{ZnCl} 2$ or $\mathrm{Zn}(\mathrm{CH} 3 \mathrm{COO}) 2$ solutions; $\mathrm{B}$ : anhydrous ethanol+ acetic acid + TBOT; C: anhydrous ethanol + acetic acid + deionized water; D: TiO2 sol-gel
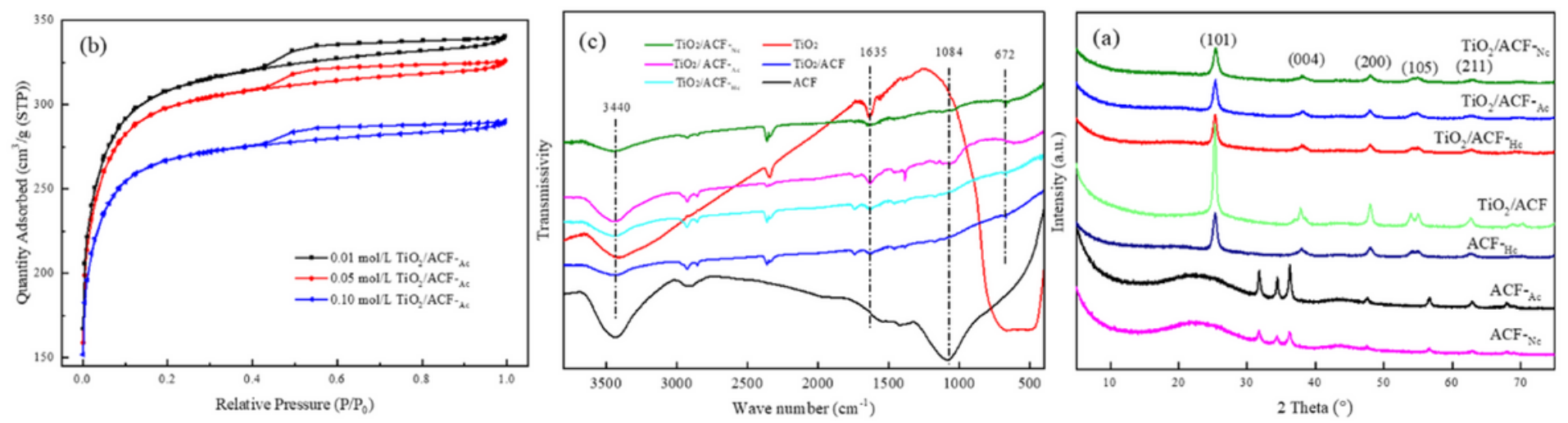

Figure 2

(a) XRD patterns, (b) N2 adsorption-desorption isotherms and (c) FT-IR spectra of composites 


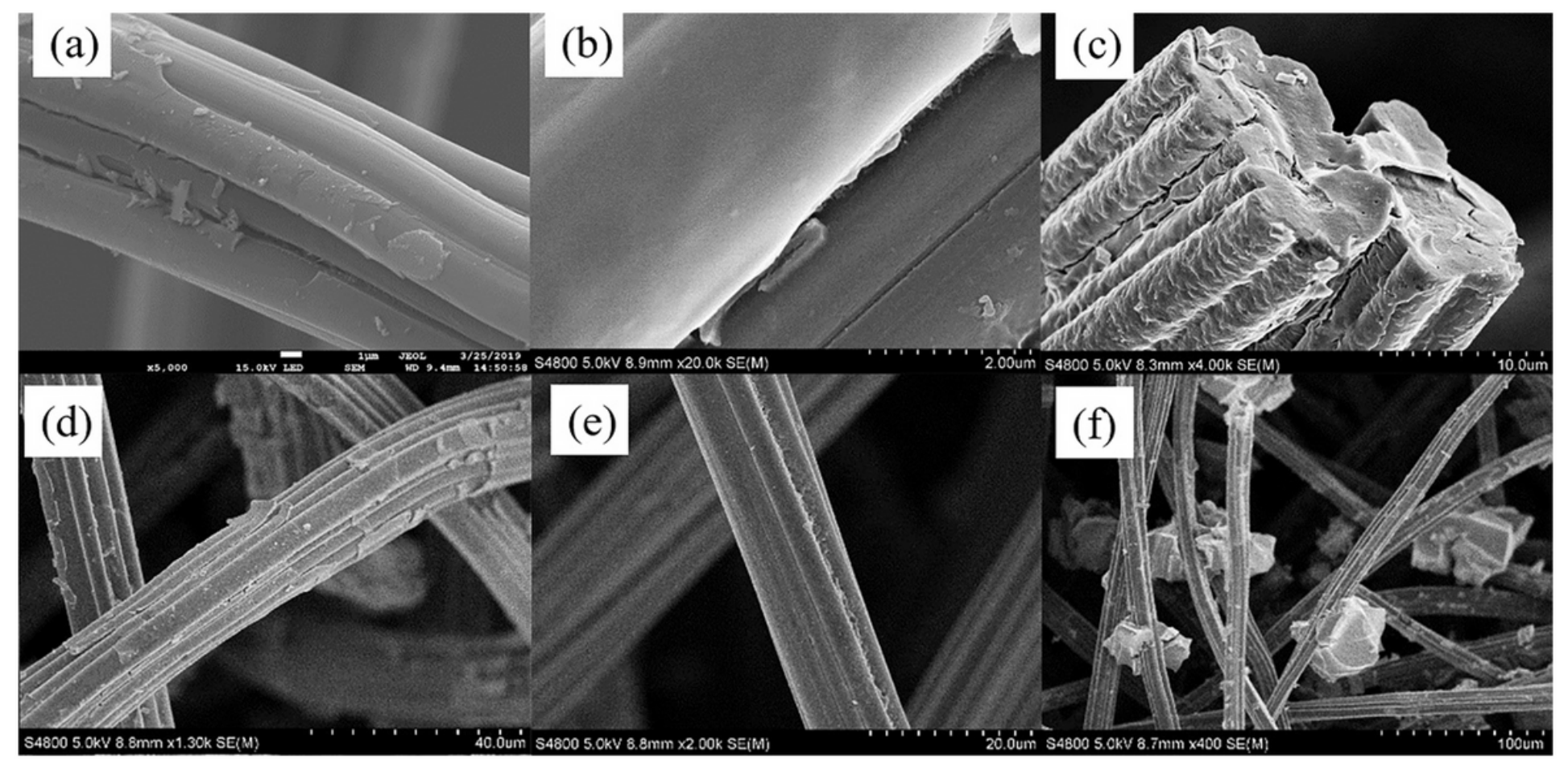

Figure 3

(a) SEM images of TiO2/ACF-Nc, (b) TiO2/ACF-Hc, (c) TiO2/ACF-Ac and Zn(CH3COO)2-ACF (d) impregnated one time, (e) two times, (f) three times 

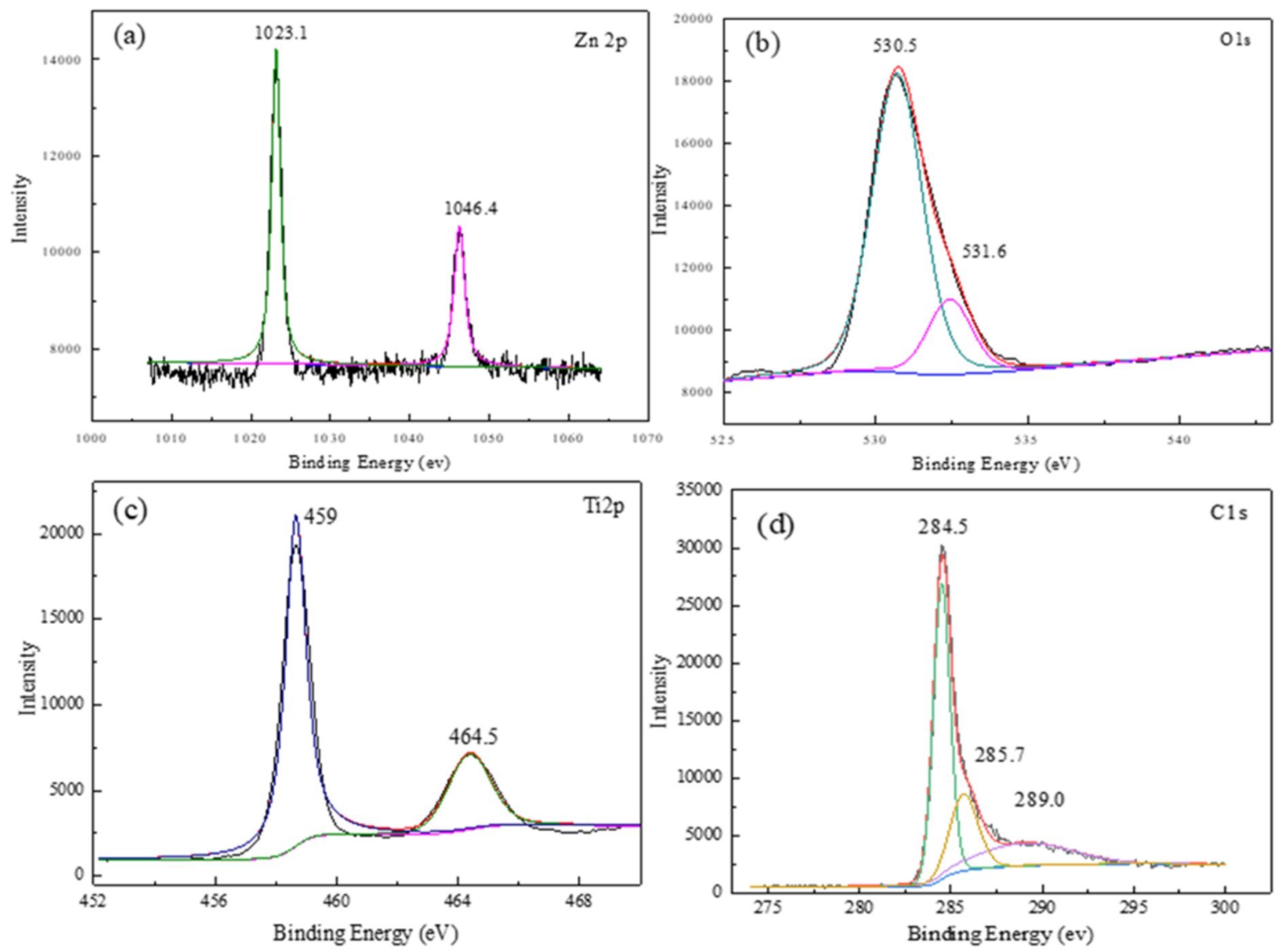

Figure 4

(a) Zn 2p core level spectra, (b) 0 1s core level spectra, (c) Ti 2p core level spectra, (d) C 1s core level spectra 

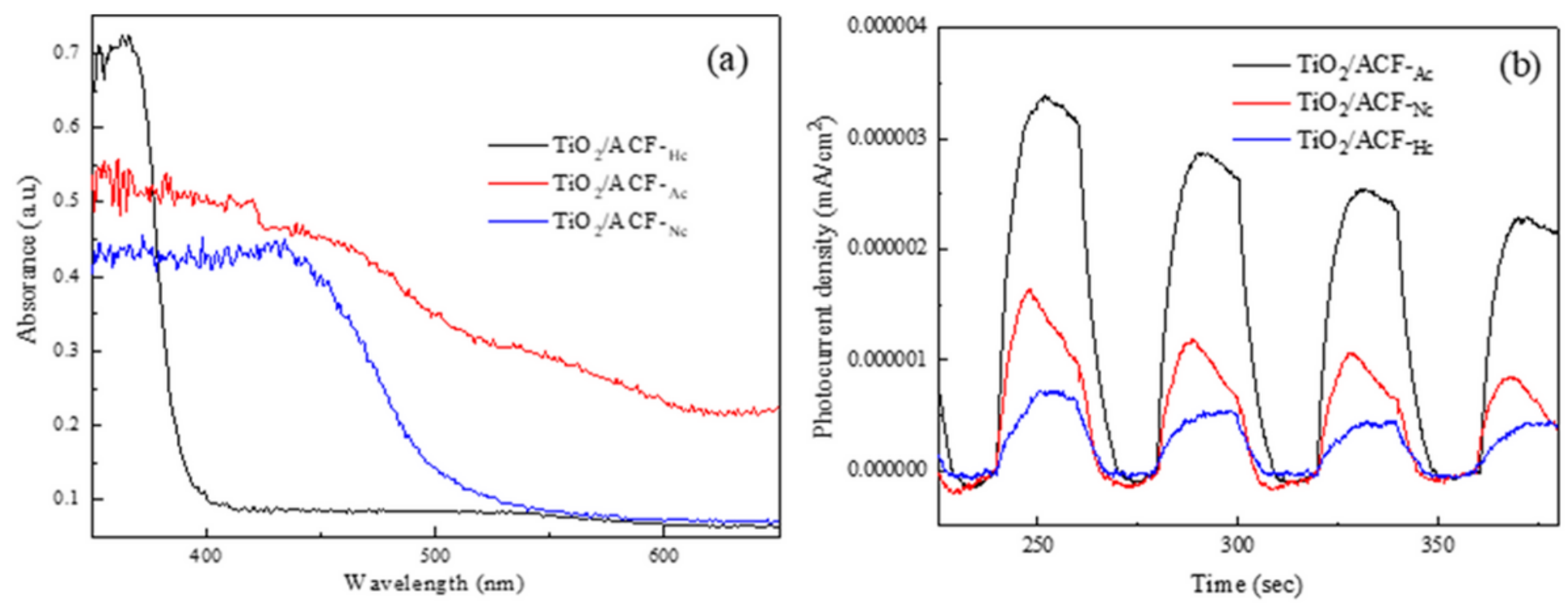

Figure 5

(a) UV-vis diffuse reflectance spectra and (b) transient photocurrent response of TiO2/ACF-Hc, TiO2/ACF-Ac and TiO2/ACF-Nc
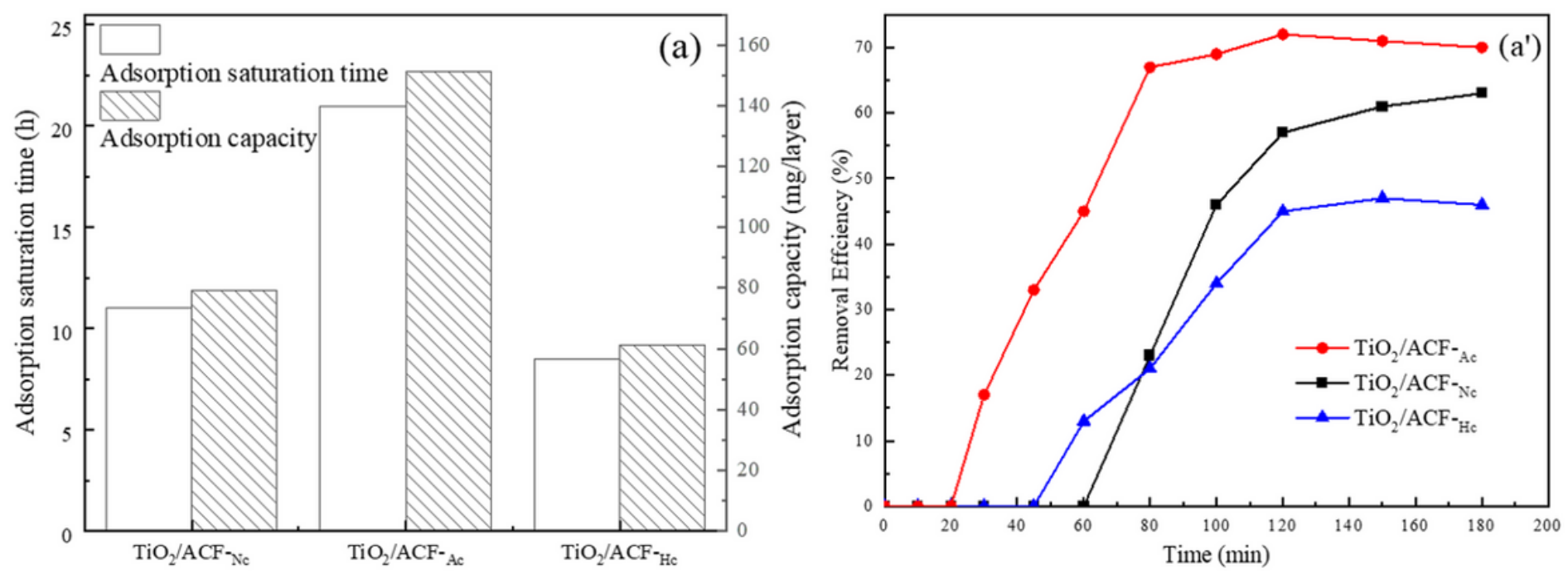

Figure 6

Effect of different zinc salts on toluene (a) adsorption and (a') photocatalytic by composites 

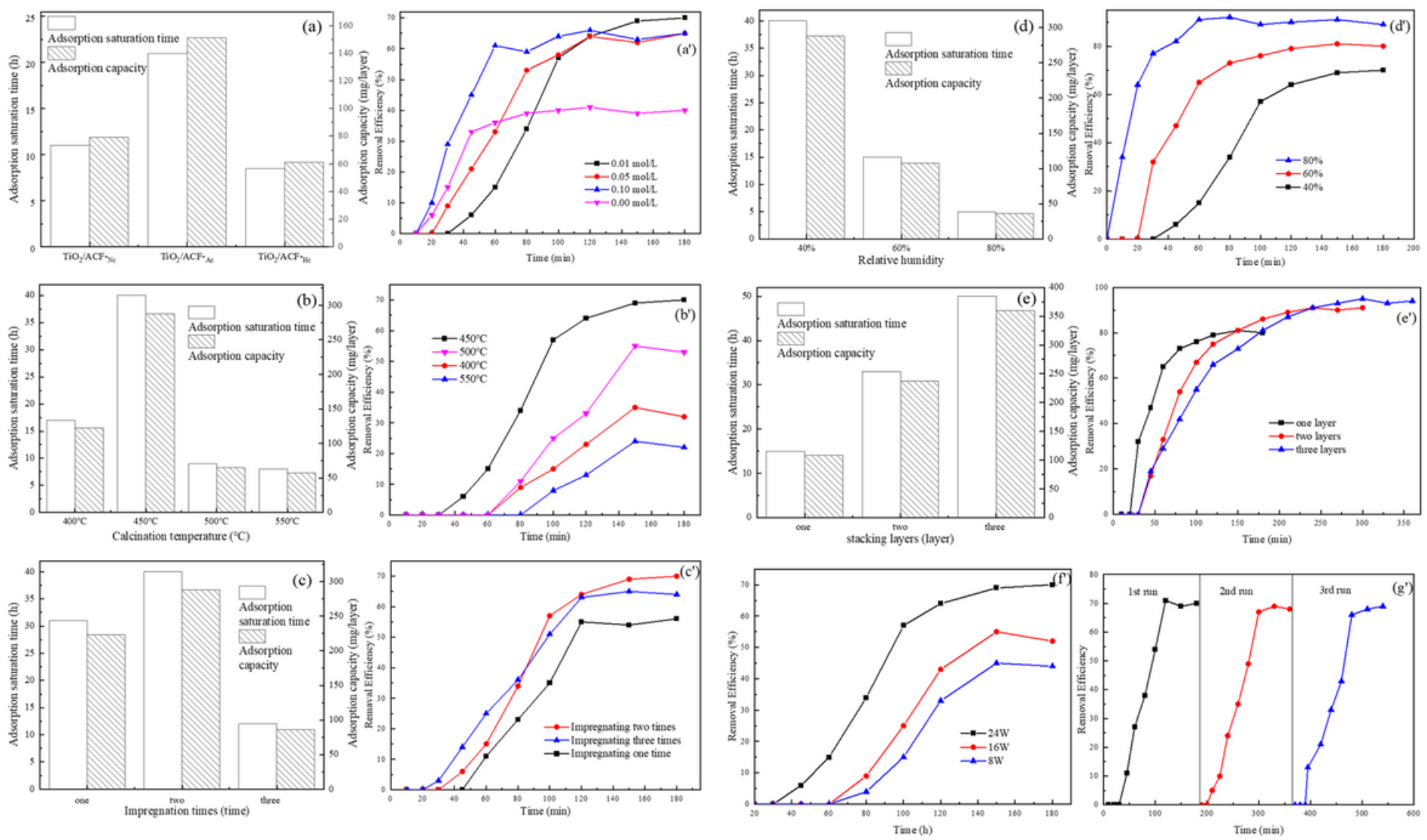

Figure 7

Effect of (a) $\mathrm{Zn}(\mathrm{CH} 3 \mathrm{COO}) 2$ concentration, (b) calcination temperature, (c) impregnation times, (d) relative humidity and (e) stack number on toluene adsorption by TiO2/ACF-Ac. Effect of (a') Zn(CH3COO)2 concentration, (b') calcination temperature, $\left(c^{\prime}\right)$ impregnation times, $\left(d^{\prime}\right)$ relative humidity, $\left(e^{\prime}\right)$ stack number, $\left(f^{\prime}\right)$ light intensity and $\left(g^{\prime}\right)$ recycling times on the photocatalytic degradation of toluene by TiO2/ACF-Ac. 


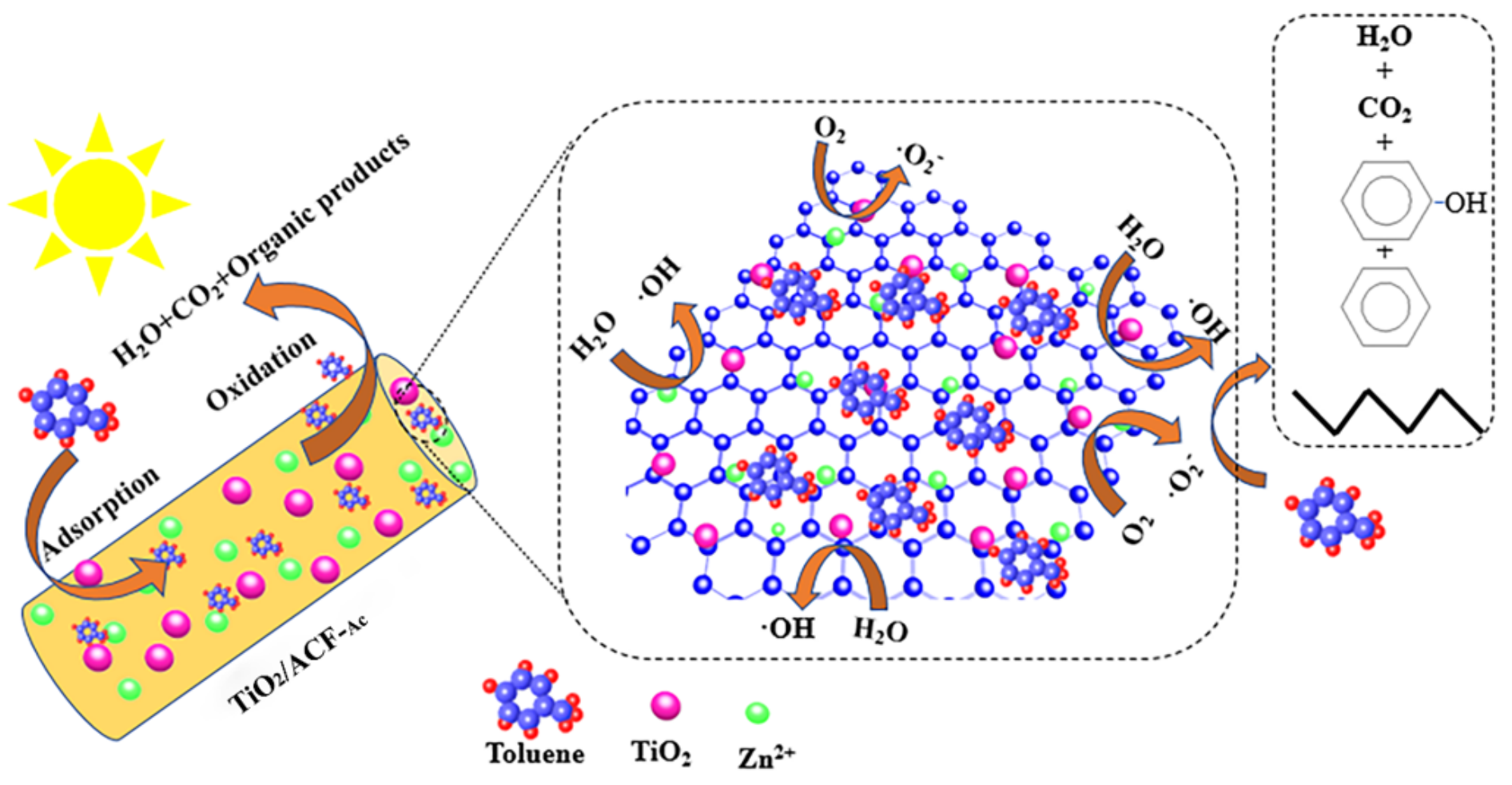

Figure 8

Mechanism illustrations of toluene adsorption and photocatalysis degration by TiO2/ACF-Ac composites

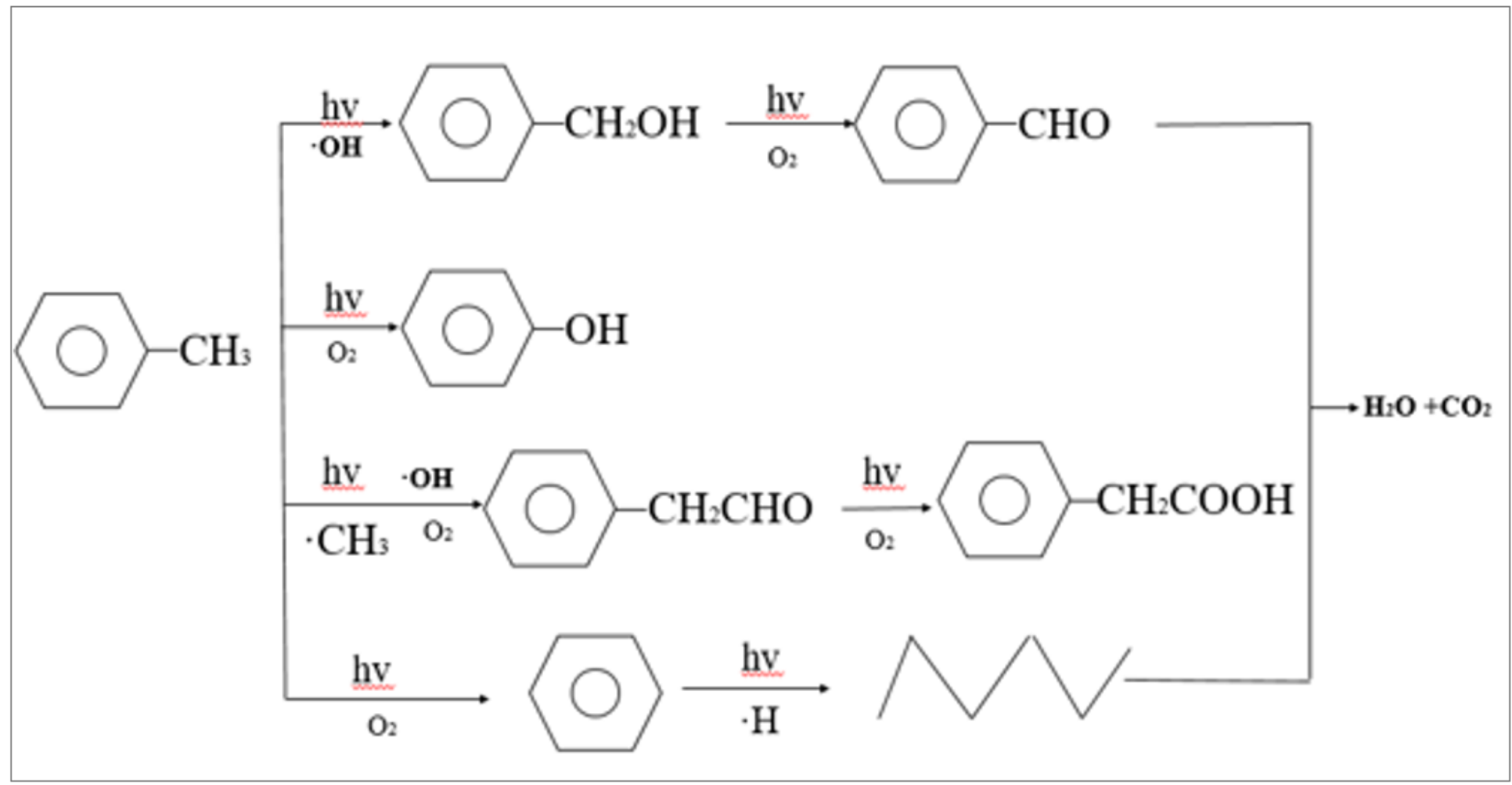

Figure 9

Toluene photocatalytic degradation reaction pathway 